\title{
Apparent digestible phosphorus in the feeding of pigs in relation to availability, requirement and environment. 1. Digestible phosphorus in feedstuffs from plant and animal origin
}

\author{
A. W. JONGBLOED \& P.A. KEMME \\ Research Institute for Livestock Feeding and Nutrition, P.O. Box 160, NL 8200 AD Lelystad, \\ Netherlands
}

Received 6 February 1990; accepted 30 March 1990

\begin{abstract}
To reduce the process of $P$-pollution, the excretion of $P$ by animals should be reduced as much as possible. Therefore the supply of $P$ with the feed should be in accordance with the animal's requirement. Therefore knowledge is required on the digestibility of $P$ in feedstuffs. The apparent digestibility of $\mathbf{P}$ in 15 kinds of feedstuffs of plant origin was measured in about 75 trials with pigs. Besides that 8 batches of feedstuffs of animal origin were tested. In most trials maize served as a basal feed. Apparent $P$ digestibility was measured using the total faeces collection technique. In each trial, four animals were used in the live weight range of 45 to $110 \mathrm{~kg}$. The concentration of digestible $P$ for the total faeces collection technique was planned not to exceed $1.6 \mathrm{~g} \mathrm{~kg}^{-1}$. In addition for 2 batches of feedstuffs of animal origin the slope ratio technique was used. The results indicate that the $P$ digestibility in feedstuffs of plant origin varies substantially. For maize, maize byproducts, rice bran and sunflower seed meal the $P$ digestibility was low, varying from 10 to $20 \%$. P digestibility of barley, beans (Phaseolus spp.) and soya bean meal solvent extracted ranged from 37 to $39 \%$ and dehulled and non-dehulled soya bean meal gave similar results. The highest $\mathrm{P}$ digestibility was obtained for wheat and peas, 47 and $45 \%$, respectively. Part of the differences in P digestibility can be explained by the proportion of phytate $\mathbf{P}$ and the presence of phytase. The $\mathbf{P}$ digestibility in feedstuffs of animal origin is high, ranging from 68 to $91 \%$. Differences in P digestibility may be due to differences in technological treatment or physico-chemical structure of the products.
\end{abstract}

Keywords: pigs, feedstuffs, digestibility, phosphorus, phytate, phytase

\section{Introduction}

Phosphorus (P) is an essential element in the animal's body. In addition to its vital participation in the development and maintenance of skeletal tissue, it plays an important role in many other metabolic functions (NRC, 1980). Usually, amounts of 
$\mathrm{P}$ available for the animal from feeds of plant origin are not sufficient to obtain good performance and may negatively affect the benefit in animal husbandry (Jongbloed, 1987). Therefore, additional inorganic phosphorus is supplied to diets, especially for pigs and poultry.

On the other hand, it has been recognized that excretion of $\mathrm{P}$ can lead to environmental problems (Gerritse \& Zugec, 1977). This is predominantly in areas with a high number of pigs and poultry per hectare of land. Application of the manure in large quantities in certain areas leads to accumulation of $P$ in the soil, together with leaching-out and run-off. The effect is eutrophication of the ground water and the sweet water resources. To reduce this process of environmental pollution, the excretion of $\mathrm{P}$ by animals should be reduced as much as possible.

As a first step the supply of $P$ with the feed should be in accordance with the animal's requirement. Therefore adequate knowledge is required on the digestibility of $\mathrm{P}$ in the feedstuffs used and on the requirement of $\mathrm{P}$ at any stage and type of production.

Secondly, the P excretion can be reduced by enhancement of the digestibility of $P$ in feeds by means of plant or microbial phytase (Simons et al., 1990).

Another possibility to decrease excretion of $P$ is a directed choice for those feedstuffs in the mixed feed which have a low total $\mathrm{P}$ concentration together with a high $P$ digestibility.

The term 'digestible P' will be used for apparently absorbable P. Only when literature is cited 'available $P$ ' is used.

In this study information is given on the $P$ digestibility of various feedstuffs from plant and animal origin. In practice up to now it is mostly assumed that $P$ availability of feedstuffs of plant origin is about 30 to $35 \%$, but it will be reported here that there is a wide range in $P$ digestibility between feedstuffs. The availability of $P$ in feedstuffs of animal origin is assumed to be $100 \%$ (NRC, 1988). Also these feedstuffs have a wider range in $\mathrm{P}$ digestibility as will be presented in this paper.

\section{Literature review}

Up to now knowledge of the digestibility (availability) of $\mathrm{P}$ from plant origin is rather scarce. Most experiments have been focussed on maize, barley, wheat, wheat bran and soya bean meal. Only one or two measurements have been reported on about 10 other feedstuffs. Furthermore, 13 trials have been reported in which a maize-soya bean meal diet without supplementary inorganic phosphate was tested for $\mathbf{P}$ digestibility. The results of these experiments have been extensively discussed by Jongbloed (1987).

Two main methods were used for assessing the availability of $P$ in feedstuffs. The first one was the slope ratio technique where animals were given graded amounts of $\mathbf{P}$ from feeds of unknown availability. The slope of the relationship between $P$ intake and bone ash or bone breaking strength was compared with that of a standard form of $\mathrm{P}$ (mostly monosodium phosphate). The availability of monosodium phosphate was assumed to be $100 \%$ (Cromwell, 1983).

The second one was a balance technique where the apparent digestibility (absorb- 
ability) was measured by the difference between $\mathbf{P}$ intake and its faecal excretion.

The results obtained by the two techniques should be discussed in combination because they can provide complementary information. It is suggested to multiply the availability figures obtained by the slope ratio technique with monosodium phosphate as a reference by 0.9 to get apparent digestibility coefficients. The factor 0.9 was chosen because from three experiments an apparent digestibility coefficient of 90 for monosodium phosphate was obtained (Jongbloed, 1987; Dellaert et al., 1990). This correction was applied to the availability figures cited in the literature and the recalculated results are presented in Table 1.

The value for maize + soya bean meal feeds was obtained after applying a proportion from 10 to $17 \%$ of soya bean meal in the feed. Average P digestibility in maize was calculated by leaving out the value of $48 \%$ obtained by Fourdin et al. (1986). Their value differed extremely from other values. Ensiled moist maize has a much higher $P$ digestibility than dry maize. This can be explained by hydrolysis of phytate by microbial phytase during the ensiling process. Wheat and wheat by-products have a considerable higher $\mathbf{P}$ digestibility than maize, barley and soya bean meal. This can be explained by the presence of wheat phytase, which has a higher activity (Pointillart et al., 1984).

Feedstuffs of animal origin usually contain a considerable concentration of protein with a high biological value. These products are also rich in $\mathrm{P}$, which is almost all in the form of inorganic phosphates. Therefore a high availability and substantial contribution to the supply of $\mathrm{P}$ for pigs may be expected.

However, bibliographic information concerning the availability of phosphorus from feedstuffs of animal origin is rather scarce. Huang \& Allee (1981) reported that the $\mathrm{P}$ availability from meat and bone meal was $93 \%$, whereas the values for fish meal and steamed bone meal found by Hew et al. (1982) amounted to 102 and $82 \%$, respectively. Also, Burnell et al. (1988) concluded that $\mathbf{P}$ from dried whey is available for $76 \%$ and from blood meal for $92 \%$.

The review shows that information on P digestibility of only a few feedstuffs is available. As in the Netherlands a lot of by-products of cereals and oil containing seeds are used in pig feeds, studies were performed with a lot of these feedstuffs.

Table 1. Recalculated apparent digestibility of $\mathrm{P}$ in some feeds and feedstuffs (Jongbloed, 1987).

\begin{tabular}{lclr}
\hline Feed or feedstuff & $\mathrm{n}$ & $\begin{array}{l}\text { Digestibility (\%) } \\
\text { (mean } \pm \text { SD) }\end{array}$ & Range \\
Maize + soya bean meal & & $30 \pm 10$ & $15-39$ \\
Barley & 13 & $32 \pm 14$ & $16-51$ \\
Maize & 6 & $17 \pm 9$ & $8-29$ \\
Maize (moist, ensiled) & 9 & $42 \pm 7$ & $36-52$ \\
Wheat & 4 & $44 \pm 4$ & $36-46$ \\
Wheat bran/middlings & 5 & $41 \pm 11$ & $32-50$ \\
Soya bean meal & 6 & $24 \pm 8$ & $15-34$ \\
\hline
\end{tabular}




\section{Experiments with pigs to determine the digestibility of $P$ in different feedstuffs}

Details of experiments with various feeds have been described by Jongbloed (1987) and by Jongbloed \& Kemme (1990). Therefore, only relevant aspects of these trials will be discussed.

\section{Materials and methods}

Most trials were performed according to a Latin square design. Altogether more than 100 batches of feedstuffs have been tested for $\mathrm{P}$ digestibility. To include a mean figure of feedstuffs from plant origin at least 3 batches per feedstuff were tested. This was not the case for feedstuffs of animal origin because almost all phosphorus is in the inorganic form. Only 1 or 2 batches have been tested so far for some feedstuffs such as lupins, wheat germ meal, wheat gluten feed meal, soya beans (full fat), ground nut expeller, cottonseed expeller, coconut meal solvent extracted, linseed expeller, linseed solvent extracted, rape seed meal solvent extracted and lucerne.

In each trial, 4 animals were used in the weight range of 45 to $110 \mathrm{~kg}$. In the trials a basal feed was used except for barley, maize and wheat, which were tested as a single feed. For the first 29 trials, barley served as a basal feed but due to the presence of some phytase in barley, which might affect the $\mathrm{P}$ digestibility, it was substituted by maize. The procedure was such that about $50 \%$ or more of the tested feedstuff should be used in addition to the basal diet, provided that the concentration of digestible $P$ in the diet should not exceed $1.6 \mathrm{~g} \mathrm{~kg}^{-1}$. This is regarded as the minimum $P$ requirement for growing pigs (Jongbloed, 1987). To balance the feeds all vitamins and essential trace elements were added. The $\mathrm{Ca} / \mathrm{P}$ ratio in the diet was maintained at 1.3 by the addition of limestone, with a concentration of $\mathrm{Ca}$ above $5.0 \mathrm{~g} \mathrm{~kg}^{-1}$. This means that diets with rice bran, wheat bran and maize gluten feed due to a relative high $P$ content also contained an increased concentration of $\mathrm{Ca}$. A total of 26 diets had a Ca concentration above $8.0 \mathrm{~g} \mathrm{~kg}^{-1}$ dry matter. In the tri-

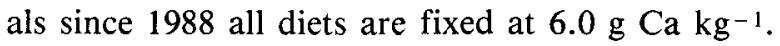

In 8 trials with animal products maize was used as a basal diet and supplemented with different animal products at a constant total Ca content in feed of $6.0 \mathrm{~g} \mathrm{~kg}^{-1}$. In addition, 2 trials were carried out using the slope ratio technique to evaluate batches of meat and bone meal, and bone precipitate (Dellaert et al., 1990).

In all trials using the balance technique the amount energy in the diet fed was 2.3 times maintenance $\left(292 \mathrm{~kJ} \mathrm{NE}_{\mathrm{f}}\right.$ or $\left.418 \mathrm{~kJ} \mathrm{ME} \mathrm{kg}{ }^{-3 / 4}\right)$. Just before feeding time about 2.51 water was added per $\mathrm{kg}$ of diet. The diet was offered twice daily in similar amounts. The procedure for sampling, weighing and analytical techniques have been described by Jongbloed \& Kemme (1990).

Digestibility of $P$ in the tested feedstuffs was calculated by difference assuming that the digestibility of $\mathrm{P}$ in the basal diet was constant and equal to the results of the trial with basal feed only. 


\section{Results}

The results of the chemical analyses in the feedstuffs of plant origin and the $\mathrm{P}$ digestibility are presented in Table 2.

The mean standard deviation of $P$ digestibility of the total ration (basal diet + tested feedstuff) over all trials was $3.8 \%$. For barley, maize and wheat, which were tested as single feeds, the mean standard deviation was slightly smaller. The mean standard deviation of $P$ digestibility of feedstuffs tested with a basal diet was $6.4 \%$. This is higher than of the total ration because usually only 50 to $80 \%$ of total digestible $\mathrm{P}$ originated from the feedstuff tested. In the case of tapioca, providing less than $30 \%$ of digestible $P$ in the whole ration, the standard deviation of $\mathrm{P}$ digestibility was much higher, i.e. $19 \%$.

Concentration of $\mathbf{P}$ between the feedstuffs differed substantially and varied between $1.4 \mathrm{~g} \mathrm{~kg}^{-1}$ dry matter (tapioca meal) and $17 \mathrm{~g} \mathrm{~kg}^{-1}$ dry matter (rice bran).

The concentration of phytate $\mathrm{P}$ as a proportion of total $\mathrm{P}$ ranged between $30 \%$ (in tapioca and beans) and $80 \%$ (in rice bran and wheat middlings). About two thirds of total $\mathbf{P}$ in barley, wheat and maize is present as phytate $\mathbf{P}$. In some other feedstuffs such as hominy feed and maize gluten feed phytate $\mathrm{P}$ concentration varied markedly, presumably due to differences in processing.

Relatively large differences in $P$ digestibility were observed between feedstuffs. The lowest $P$ digestibility was noted for tapioca meal and rice bran (10 and $12 \%$, respectively), whereas the highest values were obtained for wheat and peas (47 and

Table 2. Ca, $P$ and phytate $P$ concentration of feedstuffs tested and apparent $P$ digestibility coefficients (mean, SD and range).

\begin{tabular}{|c|c|c|c|c|c|c|c|}
\hline & \multirow{2}{*}{$\begin{array}{l}\text { Number of } \\
\text { trials }\end{array}$} & \multicolumn{3}{|c|}{ Concentration in feedstuff $\left(\mathrm{g} \mathrm{kg}^{-1}\right)$} & \multicolumn{3}{|c|}{$P$ digestibility $(\%)$} \\
\hline & & $\mathrm{Ca}$ & $\mathbf{P}$ & phytate $\mathrm{P}$ & mean & SD & range \\
\hline Barley & 5 & $1.3 \pm 0.4$ & $4.4 \pm 0.3$ & $2.8 \pm 0.2$ & 39 & 4 & $34-44$ \\
\hline Maize & 7 & $0.6 \pm 0.3$ & $3.2 \pm 0.4$ & $2.1 \pm 0.3$ & 17 & 5 & $12-26$ \\
\hline Wheat & 5 & $0.6 \pm 0.2$ & $4.1 \pm 0.4$ & $2.9 \pm 0.2$ & 47 & 2 & $45-51$ \\
\hline Beans (Phaseolus spp.) & 3 & $2.1 \pm 0.5$ & $5.2 \pm 0.4$ & $1.7 \pm 0.4$ & 38 & 10 & $29-48$ \\
\hline Peas & 4 & $1.9 \pm 1.4$ & $4.8 \pm 0.9$ & $2.4 \pm 0.7$ & 45 & 4 & $42-51$ \\
\hline Hominy feed & 7 & $2.9 \pm 3.3$ & $7.3 \pm 1.5$ & $4.9 \pm 2.0$ & 19 & 8 & $10-34$ \\
\hline Rice bran $(<3 \%$ husks $)$ & 4 & $2.7 \pm 2.7$ & $17.0 \pm 2.7$ & $13.8 \pm 3.3$ & 12 & 2 & $9-13$ \\
\hline Wheat middlings & 6 & $1.3 \pm 0.2$ & $12.0 \pm 0.8$ & $9.6 \pm 0.9$ & 28 & 6 & $18-35$ \\
\hline Maize gluten feed & 10 & $0.8 \pm 0.5$ & $9.8 \pm 1.6$ & $6.3 \pm 1.6$ & 20 & 6 & $12-32$ \\
\hline Tapioca meal & 3 & $2.8 \pm 0.4$ & $1.4 \pm 0.3$ & $0.4 \pm \mathbf{0 . 2}$ & 10 & 12 & $1-24$ \\
\hline Coconut expeller & 5 & $1.3 \pm 0.5$ & $5.8 \pm 0.2$ & $2.6 \pm 0.5$ & 34 & 8 & $25-43$ \\
\hline Maize meal solvent extr. & 4 & $0.4 \pm 0.3$ & $7.4 \pm 0.8$ & $5.4 \pm 0.3$ & 20 & 9 & $11-31$ \\
\hline $\begin{array}{l}\text { Soya bean meal solv. extr. } \\
\quad(\mathrm{XF}>7 \%)\end{array}$ & 3 & $3.7 \pm 0.7$ & $6.6 \pm 0.5$ & $4.0 \pm 0.4$ & 37 & 1 & $36-38$ \\
\hline $\begin{array}{l}\text { Soya bean meal solv. extr. } \\
\quad(\mathrm{XF}<3.5 \% \text {; dehulled })\end{array}$ & 3 & $3.7 \pm 0.6$ & $7.3 \pm 0.6$ & $4.2 \pm 0.9$ & 38 & 4 & $33-41$ \\
\hline Sunflower seed meal solv. extr. & .4 & $3.9 \pm 0.3$ & $11.6 \pm 2.1$ & $8.9 \pm 2.1$ & 16 & 1 & $14-17$ \\
\hline
\end{tabular}


Table 3. Ca and $\mathrm{P}$ concentration in feedstuffs of animal origin tested and apparent $\mathrm{P}$ digestibility coefficients $(\mathrm{B}=$ balance technique; $\mathrm{S}=$ slope ratio technique).

\begin{tabular}{|c|c|c|c|c|c|}
\hline & \multirow[t]{2}{*}{ Technique } & \multirow[t]{2}{*}{$\begin{array}{l}\text { Number of } \\
\text { trials }\end{array}$} & \multicolumn{2}{|c|}{$\begin{array}{l}\text { Concentration in } \\
\text { feedstuff }\left(\mathrm{g} \mathrm{kg}^{-1}\right)\end{array}$} & \multirow[t]{2}{*}{$P$ digestibility } \\
\hline & & & $\mathrm{Ca}$ & $\mathrm{P}$ & \\
\hline Meat meal & B & 1 & 48.6 & 22.5 & 74 \\
\hline Meat meal & B & 1 & 66.3 & 33.1 & 85 \\
\hline Bone meal & B & 1 & 174.2 & 85.7 & 68 \\
\hline Fish meal & B & 2 & 33.1 & 25.2 & 86 \\
\hline Feather meal (hydrolysed) & B & 1 & 3.6 & 1.6 & 75 \\
\hline Skimmed milk powder & B & 1 & 12.7 & 10.6 & 91 \\
\hline Whey powder (poor in lactose) & $\mathrm{B}$ & 1 & 10.6 & 14.8 & 82 \\
\hline Bone precipitate & $\mathrm{S}$ & 1 & 229.0 & 176.3 & 87 \\
\hline Meat and bone meal & $S$ & 1 & 182.2 & 87.6 & 80 \\
\hline
\end{tabular}

$45 \%$, respectively). For maize and maize by-products, such as hominy feed, maize gluten feed and maize meal solvent extracted, the $\mathbf{P}$ digestibility was low, varying from 17 to $20 \%$ (Table 2). P digestibility of barley, beans and soya bean meal solvent extracted ranged from 37 to $39 \%$. In one trial with soya bean meal a value of $51 \%$ was obtained, but this figure was regarded as an outlier. Also, in one batch of sunflower seed meal solvent extracted the apparent digestibility of $\mathrm{P}$ amounted to $38 \%$, whereas the other values for $P$ in this feedstuff were around $16 \%$.

Concentration of $\mathrm{Ca}$ and $\mathrm{P}$ in all the tested products of animal origin and the apparent digestibility coefficients of $P$ are presented in Table 3 . The observed $\mathrm{Ca} / \mathrm{P}$ ratio was nearly 2 for meat meal, bone meal and meat + bone meal. For fish meal and skimmed milk powder it ranged between 1.2-1.3 and in whey powder (poor in lactose) the $\mathrm{Ca} / \mathrm{P}$ ratio was 0.7 .

The apparent $P$ digestibility in those feedstuffs is high, ranging from 68 to $91 \%$. The values are quite close to those obtained for feed-grade phosphates (Dellaert et al., 1990).

\section{Discussion}

Comparison of the coefficients of apparent $\mathbf{P}$ digestibility presented in Table $\mathbf{1}$ and in Table 2 lead to a conclusion that only for some feedstuffs there is a good agreement between literature and our own results.

Digestibility of $\mathrm{P}$ from barley used in our trials was not significantly different from that cited in the literature (39 vs $32 \%$ ). In our trials there was a tendency for a higher $P$ digestibility with a lower proportion of phytate $P$.

Maize by-products contain 2 to 3 times more $\mathrm{P}$ than maize itself, but the apparent digestibility was very similar (17 and $20 \%$, respectively). It indicates that about $80 \%$ of $\mathrm{P}$ from the maize by-products is excreted in faeces.

The apparent digestibility of $\mathbf{P}$ in wheat was relatively high both in literature 
(44\%) and our own trials $(47 \%)$. This may be attributed to a high phytase activity as suggested by Fourdin et al. (1986). In our trials it was found that wheat contained about 1000 phytase units per $\mathrm{kg}\left(1\right.$ unit $=$ release of one $\mu$ mol inorganic $\left.\mathbf{P} \min ^{-1}\right)$, which is rather high.

In contrast to data on wheat bran/middlings from the literature, we obtained a markedly lower value ( 41 vs $28 \%$ ). Phytase activity measured for some batches of wheat middlings ranged between 3700 and 5100 units. Also, there was a relatively large variation in $\mathbf{P}$ digestibility of wheat bran. Recent trials elucidated that, apart from differences in phytase activity, presumably a high calcium concentration in the diet significantly diminished $P$ absorbability (unpublished results). Jongbloed (1987) and Jongbloed \& Kemme (1990) reported that a calcium level exceeding $10 \mathrm{~g} \mathrm{~kg}^{-1}$ in the diet may depress $\mathbf{P}$ digestibility of wheat bran.

Peas and beans have a rather high $P$ digestibility, which can partly be explained by a relatively low concentration of phytate $P$.

The extremely low value for tapioca meal $(10 \%)$ was mainly due to the small amount of $P$ in this feedstuff, but might also be affected by a relatively high proportion of endogenous $\mathbf{P}$ in total intake of $\mathrm{P}$.

In our trials the $\mathrm{P}$ digestibility of soya bean meal solvent extracted was superior to the value from literature. We assume that the value in the literature underestimates its $\mathrm{P}$ digestibility. Assuming that the $\mathrm{P}$ digestibility for maize is correct $(17 \%)$ and the $\mathrm{P}$ digestibility for a maize-soya bean meal diet is $30 \%$ (Table 1), then it can be estimated that the value for soya bean meal should be at least $40 \%$.

According to NRC (1988) the availability of P in soya bean meal and dehulled soya bean meal is 38 and $25 \%$, respectively, whereas our studies prove that both feedstuffs have similar P digestibility ( 37 and $38 \%$ ). Based on the phytate P content in the feedstuffs and assuming that non-phytate $\mathrm{P}$ in the feedstuffs is absorbed for $80 \%$, it was calculated that no $\mathrm{P}$ bound to phytate complexes has been absorbed from most of the feedstuffs. However, from wheat, wheat middlings and barley, which contain phytase, some $\mathrm{P}$ from phytate $\mathrm{P}$ has been absorbed. Similar conclusions were drawn by Pointillart et al. (1984) and Fourdin et al. (1986; 1988).

Due to the high concentration of $\mathrm{P}$ in bone meal it seems that the balance technique is less suitable for experiments on this meal with growing-finishing pigs. To obtain a level of less than $1.6 \mathrm{~g}$ digestible $\mathbf{P}$ in the feed, only a small amount of bone meal can be added to the basal diet and therefore the analytical error is relatively high.

Re-evaluating the bibliographic data of the $\mathrm{P}$ availability in fish meal, meat + bone meal and steamed bone meal according to its digestibility coefficients (availability coefficients $\times 0.9$ ) it was obtained 92,84 and $74 \%$, respectively. These values are slightly higher than those presented in Table 3 , except for dried whey. Variability of $P$ content in the compared batches of the same feedstuff might be due to differences in technologies of manufacturing and so digestibility of $P$.

It seems likely that the $\mathrm{P}$ digestibility in bone precipitate is higher than in steamed bone meal, which may arise from differences in physico-chemical structure of the products. 


\section{Conclusion}

Our results indicate that the digestibility of $\mathrm{P}$ in various feedstuffs of plant origin varies substantially. Factors which cause variation in $\mathrm{P}$ digestibility between feedstuffs are the origin of the feedstuff, the concentrations of phytate $\mathrm{P}$ and of total $P$ and the presence of phytase. The digestibility of $P$ in maize, maize by-products, rice bran and sunflower seed meal is $20 \%$ or lower and thus substantially lower than the generally accepted value between 30 and $35 \%$. However, in the case of wheat (phytase-rich) and peas these values are largely underestimated.

At least three values should be gathered for feedstuffs of plant origin not mentioned in Table 2 to work out a good basis for reliable tabular data on digestible $P$ that can be applied for practice.

The apparent digestibility of $\mathrm{P}$ in feedstuffs of animal origin is high and ranges from 70 to $90 \%$. These feedstuffs can supply high amounts of digestible $P$ in diets for pigs. More observations are needed for each animal product to justify whether the $\mathrm{P}$ digestibility is below or above $80 \%$. From presented results it can be concluded that $\mathrm{P}$ from meat meal, bone meal as well as meat and bone meal is digested around $80 \%$.

\section{Acknowledgements}

This work was supported by the Dutch Commodity Board for Feedstuffs and the Dutch Fund for Manure Research. The advice of members of the Phosphorus Working Group is gratefully acknowledged.

\section{References}

Burnell, T. W., G. L. Cromwell \& T. S. Stahly, 1988. Bioavailability of phosphorus in dried whey, blood meal and distillers grains for pigs. Journal of Animal Science 66 (Suppl. 1):262.

Cromwell, G. L., 1983. Biological availability of the phosphorus in feedstuffs for nonruminants. Proceedings of the National Feed Ingredient Association, Mineral Nutrition Institute, Chicago, III. NFIA, Des Moines, IA.

Dellaert, B. M., G. F. V. van der Peet, A. W. Jongbloed \& S. Beers, 1990. A comparison of different techniques to assess biological availability of feed phosphates in pig feeding. Netherlands Journal of Agricultural Science 38: 555-566.

Fourdin, A., N. Fontaine \& A. Pointillart, 1986. Importance de l'activité phytasique des céréales pour l'utilisation des phytates par le porc: comparison triticale et mais. Journées Recherches Porcines en France 18: 83-90.

Fourdin, A., P. Camus, B. Cayron, C. Colin \& A. Pointillart, 1988. Amélioration de l'utilisation des phytates chez le porc par incorporation d'issues a haute activité phytasique: son de seigle, son de blé. Journées Recherches Porcines en France 20: 327-332.

Gerritse, R. G. \& I. Zugec, 1977. Phosphorus cycle in pig slurry measured from 32PO4 distribution rates. Journal of Agricultural Science (Cambridge) 88: 101-109.

Hew, V. F., G. L. Cromwell \& T. S. Stahly, 1982. The bioavailability of phosphorus in some tropical feedstuffs for pigs. Journal of Animal Science 55 (Suppl. 1):277.

Huang, K. C. \& C. L. Allee, 1981. Bioavailability of phosphorus in selected feedstuffs for young chicks and pigs. Journal of Animal Science 53 (Suppl. 1):248-249. 
Jongbloed, A. W., 1987. Phosphorus in the feeding of pigs; effect of diet on the absorption and retention of phosphorus by growing pigs. Doctoral Thesis, Wageningen Agricultural University, $343 \mathrm{pp}$.

Jongbloed, A. W. \& P. A. Kemme, 1990. Effect of pelleting mixed feeds on phytase activity and the apparent absorbability of $\mathrm{P}$ and Ca in pigs. Animal Feed Science and Technology 28: 233-242.

NRC, 1980. Mineral tolerance of domestic animals. National Academy of Science, Washington DC, $577 \mathrm{pp}$.

NRC, 1988. Nutrient requirements of swine. Ninth revised edition. National Academy Press, Washington DC, $93 \mathrm{pp}$.

Pointillart, A., N. Fontaine \& M. Thomasset 1984. Phytate phosphorus utilization and intestinal phosphates in pigs fed low phosphorus: wheat or corn diets. Nutrition Reports International 29: 473-483.

Simons, P. C. M., H. A. J. Versteegh, A. W. Jongbloed, P. A. Kemme, P. Slump, K. D. Bos, M. G. E. Wolters, R. F. Beudeker \& G. J. Verschoor, 1990. Improvement of phosphorus availability by microbial phytase in broilers and pigs. British Journal of Nutrition. (In press). 